CONTI, J.H.; TAVARES, F.C.A. Alterações fenotípicas em cultivares de alface selecionadas para calor. Horticultura Brasileira, Brasília, v. 18, n. 3, p.159163 , novembro 2.000 .

\title{
Alterações fenotípicas em cultivares de alface selecionadas para calor.
}

\author{
José Henrique Conti; Flavio C.A. Tavares ${ }^{1}$ \\ ${ }^{1}$ USP-ESALQ, Dep ${ }^{\text {to }}$. de Genética, C. Postal 83, 13.418-900 Piracicaba-SP. e.mail: jhconti@carpa.ciagri.usp.br.
}

\section{RESUMO}

Cultivares de alface selecionadas para o pendoamento lento e as mesmas que lhes deram origem foram analisadas quanto a variações morfológicas, com o objetivo de quantificar possíveis modificações adaptativas para as condições de cultivo em épocas de calor. Cultivares dos grupos "manteiga" (Regina, Glória, IAC 303, IAC 202, Sem Rival e Luciana) "folha crespa" (Grand Rapids e Brisa) e "americana" (Great Lakes e Mesa 659), foram avaliadas em dois plantios de verão, em Piracicaba, em delineamento de blocos casualizados. No primeiro experimento, (novembro/90), foram avaliadas as características de número de estômatos, espessura de folha e quantidade de clorofila total. No segundo, (setembro/91), foram avaliados o peso seco, peso fresco, porcentagem de matéria seca, tempo para pendoamento e número de folhas. As cultivares selecionadas para calor no grupo "manteiga" (Glória e Regina), apresentaram maior número de estômatos (respectivamente $9487 / \mathrm{cm}^{2}$ e $7973 / \mathrm{cm}^{2}$ ) e folhas mais grossas (respectivamente $556 \mathrm{~mm}$ e $439 \mathrm{~mm}$ ) e também, acumularam maior quantidade de matéria seca (respectivamente $24,55 \mathrm{~g}$ e $25,50 \mathrm{~g}$ ). A cultivar selecionada para calor do grupo "folha crespa" (Brisa) acumulou maior quantidade de matéria verde $(446,77 \mathrm{~g})$ e seca $(22,40 \mathrm{~g})$, da mesma forma que apresentou maior quantidade de estômatos $\left(7.279 / \mathrm{cm}^{2}\right)$. Para as cultivares do grupo "americana", observou-se diferença significativa apenas para espessura de folha, sendo que a cultivar Mesa 659 apresentou folhas mais grossas $(589 \mathrm{~mm})$. Constataram-se aumentos significativos da biomassa vegetal nas cultivares selecionadas para calor em relação àquelas não selecionadas. As cultivares que atingiram maior produtividade de matéria seca por planta foram Mesa 659 (28,74 g), Great Lakes $(27,17 \mathrm{~g})$ e Regina. Os resultados comprovaram que a seleção para o pendoamento lento indiretamente produziu variações adaptativas nas plantas de alface.

Palavras-chave: Lactuca sativa L., melhoramento, estômatos, clorofila, peso seco, peso fresco, grupos varietais, pendoamento tardio.

\section{ABSTRACT \\ Phenotypical alterations in lettuce genotypes selected for heat tolerance.}

Lettuce cultivars selected for slow bolting and unselected ones of the same groups were analyzed for morphological variations, to quantify possible adaptative modifications for the cultivation conditions in heat seasons. Cultivars of the groups "butterhead" (Regina, Glória, IAC 303, IAC 202, Sem Rival and Luciana), "leaflettuce" (Grand Rapids and Brisa), and "crisphead" (Great Lakes and Mesa 659) were compared in two summer seasons, in Piracicaba, Brazil, in randomized blocks design. In the first (November/1990) were analyzed the characteristics of stomata number, leaf thickness and amount of chlorophyl of the whole plants. In the second (September/1991), were analyzed the characteristics of number of leaves, and dry and fresh weight of the whole plants. Cultivars selected for heat tolerance in the "butterhead" group (Gloria and Regina), presented larger stomata number (respectively $9,487 / \mathrm{cm}^{2}$ and $7,973 / \mathrm{cm}^{2}$ ) and thicker leaves (respectively $556 \mathrm{~mm}$ e $439 \mathrm{~mm}$ ) and, also, they accumulated larger amount of dry matter (respectively $24.55 \mathrm{~g}$ and $25.50 \mathrm{~g}$ ), Cultivars selected for heat of the group "leaflettuce" (Brisa), accumulated larger amount of green matter $(446.77 \mathrm{~g})$ and dry ones $(22.40 \mathrm{~g})$, in the same way that presented larger stomata number $\left(7,279 / \mathrm{cm}^{2}\right)$. For the cultivars of the group "crisphead", significant difference was just observed for leaf thickness; cv. Mesa 659 presented thicker leaves $(589 \mathrm{~mm})$. Significant increases of vegetal biomass were verified in cultivars selected for heat in relation to the unselected ones. Cultivars that reached larger dry matter yield were Mesa 659 (28.74 g), Great Lakes (27.17 g) and Regina. The results checked that the slow bolting selection indirectly produced adaptative variations in the lettuce plants.

Keywords: Lactuca sativa L., breeding, stomata, chlorophyll, dry weight, fresh weight, variety groups, slow bolting.

\section{(Aceito para publicação em 10 de agosto de 2.000)}

$\mathrm{Q}^{-}$ uando em cultivo sob condições de temperatura elevada, plantas de alface passam precocemente da fase vegetativa para a reprodutiva, emitindo as inflorescências ou "pendões". Nesta situação, a colheita precisa ser antecipada, o que resulta em produtos de qualidade inferior e prejuízos para o produtor (Whitaker \& Ryder, 1974). Por vários anos, sem dispor de cultivares tolerantes ao calor, nas principais regiões produtoras do Brasil o cultivo da alface ficou limitado aos períodos de inverno no Centro-sul e nas demais regiões brasileiras. O desenvolvimento de cultivares de alface adaptadas ao cultivo de verão tornou-se então objeto de programas de melhoramento, uma vez que a hortaliça é consumida durante o ano todo e apresenta grande valor econômico. Nestes trabalhos, bem sucedidos, cultivares dos grupos "manteiga" ou "cabeça lisa", tradicionais da Europa, foram intercruzadas com cultivares de pendoamento tardio, realizando-se a seleção de plantas com pendoamento tardio, em plantios de verão (Pinto \& Costa, 1977). Trabalhos de seleção obedecendo a estes critérios resultaram em várias cultivares importantes para os produtores, dentre elas, IAC 303 e IAC 202 (Nagai, 1979) e Gloria e Regina (Vecchia \& Kikuchi, 1989). 
Para as plantas do grupo "folha crespa", dispõe-se da cultivar Brisa, obtida a partir de seleção de plantas de pendoamento tardio deste grupo e da cultivar Grand Rapids. As cultivares Grandes Lagos e Mesa 659 pertencem ao grupo "americana". Estas e outras alfaces cultivadas, principalmente na California, apresentam as caraterísticas de tolerância a baixa umidade do ar e às oscilações térmicas entre o dia e a noite. Segundo Ryder (1982), as características das alfaces "americanas" são a boa tolerância ao pendoamento precoce e a resistência à queima-dos-bordos ("tip burn").

O melhoramento para obtenção de cultivares de alface adaptadas ao cultivo em épocas quentes é objetivo de diversos trabalhos em outros países. Damarany (1992), para estender a época de produção da alface no Egito, cruzou a cultivar Balady com outros quinze genótipos e as gerações F1, F2 e F3 foram avaliadas pelo número de dias do transplante em que 50\% apresentaram a primeira flor e pela quantidade de peso fresco, tendo obtido cultivares mais produtivas e com pendoamento tardio. Gong (1998), na China, obteve as linhagens 9544-1 de cabeça crespa e 9608-2 de cabeça lisa por meio da seleção de plantas individuais que apresentaram formação de cabeça e pendoamento tardio no verão. Estas linhagens foram mais resistentes ao calor e ao pendomento do que as cultivares Olympia e Summer Bibb e apresentaram altas produções e boa aceitação no mercado. LiHong \& ShiJun (1995) estudaram a base fisiológica da resistência ao calor em cultivares de alface tendo verificado que a resistência ao calor estava relacionada à menor temperatura foliar e a altas taxas de transpiração em épocas quentes.

A seleção indireta acontece em quase todos os programas de melhoramento, incluindo caracteres correlacionados positiva e negativamente, como aqueles alterados mesmo quando não considerados pelos melhoristas (Messeguer et al., 1991). No melhoramento de alfaces adaptadas ao verão, de acordo com Pinto \& Costa (1977), as plantas selecionadas devem apresentar o tipo varietal característico, além de pendoamento tardio, boa resistência ao dilaceramento de folhas e resistência à queima-dos-bordos. Observa-se que estas características estão associadas à tolerância ao calor e à forte precipitação, como acontece no verão do Centro-sul brasileiro. Com este critério de seleção, em princípio, seria esperado que as cultivares desenvolvidas apresentassem outras modificações morfo-fisiológicas, que não foram da atenção do melhorista e portanto, indiretamente selecionadas. Esta hipótese foi experimentalmente avaliada neste trabalho, que teve o objetivo de comparar cultivares de alface selecionadas para o plantio de verão com aquelas que lhes deram origem, visando identificar algumas das diferenças fenotípicas produzidas indiretamente pela seleção para pendoamento tardio. Arbitrariamente estudaram-se algumas características da planta e das folhas de alface, supostamente consideradas como alvo indireto da seleção, visando quantificar possíveis modificações adaptativas para as condições de cultivo no verão. Os estudos foram feitos com alfaces comerciais cultivadas no Brasil, portanto extensivamente avaliadas em condições reais de produção. Adicionalmente, espera-se que o conhecimento das modificações causadas indiretamente pelo melhoramento, possam fornecer subsídios para orientar novos e atuais trabalhos de melhoramento tanto em alface, como em outras espécies.

\section{MATERIAL E MÉTODOS}

Foram estudadas dez cultivares de alface e que são representativas dos três principais grupos varietais cultivados no Brasil. O grupo varietal "folha crespa" foi representado pelas cultivares Grand Rapids e Brisa, a primeira originária da Europa, portanto considerada como sem adaptação ao verão dos trópicos e, a segunda, selecionada para verão do Centro-sul brasileiro. O grupo "manteiga" ou "cabeça lisa" foi avaliado através das cultivares Sem Rival e Luciana, tidas como não adaptadas ao cultivo de verão; as cultivares IAC 303 e IAC 202, consideradas como adaptadas ao cultivo em regiões de verão ameno (Nagai, 1979); e as cultivares Gloria e Regina, que foram selecionadas para o pendoamento tardio e são consideradas como adaptadas ao cultivo de verão
(Vecchia \& Kikuchi, 1989). Dentro do grupo "americana" ou "cabeça crespa" foram avaliadas as alfaces Great Lakes e Mesa 659, que são cultivares consideradas adaptadas ao calor nos Estados Unidos, sendo a cultivar Mesa 659 mais tolerante (Ryder, 1982).

Neste trabalho alguns caracteres das plantas foram avaliados, procurando identificar aqueles relacionados ao crescimento das plantas e a características das folhas envolvidas com a fotossíntese e evapotranspiração. Foram realizados dois experimentos em campo do Departamento de Genética da Escola Superior de Agricultura Luiz de Queiroz (USP), em Piracicaba. As mudas foram formadas sob estufa em bandejas de isopor. Os tratos culturais obedeceram às recomendações técnicas recomendadas por Lisbão (1990). Piracicaba está localizada na latitude de $22^{\circ}$ e $43^{\prime}$ e longitude de $47^{\circ}$ e $37^{\prime}$, a uma altitude de 505 m sobre o nível do mar e o clima é do tipo Cwa segundo classificação pelo sistema internacional de Koeppen. A letra "C" da classificação de Koeppen significa que a temperatura média do mês mais frio é inferior a $18^{\circ} \mathrm{C}$. A letra "w" significa que a região tem uma média pluviométrica menor que $30 \mathrm{~mm}$ no mês mais seco e o "f" significa mais que $30 \mathrm{~mm}$ de chuva no mês mais seco. Quanto à temperatura, a subdivisão é feita em "a" e "b" respectivamente, temperaturas médias superiores e inferiores a $22^{\circ} \mathrm{C}$ no mês mais quente do ano (Setzer, 1966). O primeiro experimento foi plantado em 14 de novembro de 1990, quando as mudas estavam com 23 dias de desenvolvimento, em blocos casualizados, com quatro repetições. $\mathrm{O}$ experimento foi plantado em quatro canteiros, cada um representando um bloco e contendo dez cultivares com quatro plantas por cultivar, perfazendo um total de 40 plantas por canteiro. Foram amostradas três folhas de alface de mesmo tamanho em cada parcela, obtidas após 45 dias de desenvolvimento e analisadas para as características de número de estômatos, espessura da folha e quantidade de clorofila total.

O segundo experimento foi plantado em 26 de setembro de 1991, quando as mudas estavam com 25 dias de desenvolvimento, em blocos casualizados 
Tabela 1. Número médio de estômatos, quantidade de clorofila e espessura de folha em dez cultivares de alface. Piracicaba, ESALQ, 1990.

\begin{tabular}{|c|c|c|c|c|c|c|}
\hline \multirow{2}{*}{$\begin{array}{c}\text { Cultivares } \\
\text { Grand Rapids }\end{array}$} & \multirow{2}{*}{$\begin{array}{c}\text { Grupo } \\
\text { folha crespa }\end{array}$} & \multicolumn{2}{|c|}{$\begin{array}{l}\text { Número de } \\
\text { estômatos/ } \\
\text { cm2 }\end{array}$} & $\begin{array}{l}\text { Quantidade } \\
\text { de clorofila } \\
\text { (mg/l) }\end{array}$ & \multicolumn{2}{|c|}{$\begin{array}{c}\text { Espessura } \\
\text { de folha } \\
(\mathrm{mm})\end{array}$} \\
\hline & & 6585 & c & 144 & 282 & $\mathrm{fg}$ \\
\hline Brisa & folha crespa & 7279 & $\mathrm{~b}$ & 171 & 298 & ef \\
\hline Mesa 659 & americana & 5765 & ef & $293 a$ & 589 & $a$ \\
\hline Great Lakes & americana & 5324 & $f$ & $277 a b$ & 423 & c \\
\hline Sem Rival & manteiga & 4405 & $g$ & 221 & 274 & g \\
\hline Luciana & manteiga & 6017 & def & $280 a b$ & 360 & $d$ \\
\hline IAC 303 & manteiga & 5689 & ef & $268 a b$ & 306 & e \\
\hline IAC 202 & manteiga & 6396 & de & $283 a$ & 368 & $d$ \\
\hline Glória & manteiga & 9487 & $a$ & $252 \mathrm{~b}$ & 556 & $b$ \\
\hline Regina & manteiga & 7973 & $\mathrm{~b}$ & 223 & 439 & $\mathrm{C}$ \\
\hline CV \% & & & 7,47 & 7,44 & & 43 \\
\hline
\end{tabular}

*/ Médias seguidas de mesma letra nas colunas não diferem estatisticamente entre si a $5 \%$ de probabilidade pelo teste de Duncan.

com três repetições. O experimento foi plantado em seis canteiros, cada um com três blocos e dez cultivares em cada bloco, perfazendo um total de 90 plantas por canteiro. Cada canteiro teve uma linha de plantas em toda a volta para bordadura. A coleta de folhas para análise foi feita semanalmente, durante seis semanas. Durante o período de colheita, foram amostradas três plantas por parcela de cada cultivar. Para determinação do peso, semanalmente foi colhido um canteiro, perfazendo um total de seis semanas. A cada semana o material foi medido e pesado, obtendo-se dados para peso fresco, peso seco, porcentagem de matéria seca e número de folhas total.

As amostras para a análise do número de estômatos foram obtidas colocando-se a face dorsal das folhas, entre a nervura central e os bordos da folha, sobre uma lâmina com cola durante 15 segundos. A cutícula da folha foi então retirada e visualizada em microscópio ótico, fazendo-se dez contagens do número de estômatos por campo visual.

As amostras para análise da espessura das folhas foram retiradas das regiões próximo à nervura central, meio da folha e próximo aos bordos da folha. Após a retirada do material foi feito o corte com uma lâmina bisturi com a folha de alface presa entre duas lâminas de cerne de embaúba. A espessura foi medida com o auxílio do microscópio ótico. A quantidade de clorofila foi medida em espectrofotômetro, de acordo com recomendação de Whitman et al. (1971). O peso fresco foi medido em balança Mettler, cortando-se semanalmente a parte aérea de 90 plantas durante seis semanas. Em seguida determinouse o peso seco das amostras, após a exposição ao ar durante doze horas e secagem em estufa a $53^{\circ} \mathrm{C}$ por 72 horas. A porcentagem de matéria seca foi obtida da relação entre o peso seco e o peso fresco das plantas de alface. $\mathrm{O}$ número total de folhas foi contado a partir da primeira folha comercial, isto é, aquela que apresentava as condições mínimas de ser utilizada pelo consumidor final. O tempo para pendomento foi avaliado por análises diárias nas plantas a partir do $42^{\underline{0}}$ dia. Quando a metade das plantas de cada cultivar mostrava-se em início de desenvolvimento do pendão floral anotava-se a data como sendo o início do pendoamento.

As cultivares foram avaliadas pelos testes de comparação de médias de Tukey e Duncan.

\section{RESULTADOS E DISCUSSÃO}

O número de estômatos variou entre 4.405 e $9.487 / \mathrm{cm}^{2}$ de superfície da folha, o que permite indiretamente inferir que deve existir grande variação nas taxas de evapotranspiração. No es- tudo de espécies adaptadas a regiões das Montanhas Rochosas (EUA), denominadas de "alpinas" e "sub alpinas", Smith \& McClean (1989) verificaram que há uma grande pressão de seleção para a capacidade de reter água na folha, concluindo que aquelas espécies com pouca capacidade de reter água nas folhas tinham maior número de estômatos. Estes resultados demonstraram que plantas adaptadas a condições de alta transpiração também possuem elevado número de estômatos. Isto também foi observado com alfaces cultivadas no Brasil, onde as cultivares do grupo "folha crespa", apresentam uma variação de 6.585 a 7.279 estômatos $/ \mathrm{cm}^{2}$, sendo que a cultivar Brisa, selecionada para calor, apresentou uma quantidade de estômatos significativamente mais alta (Tabela 1). As cultivares "americanas", ambas selecionadas para condições de calor nos Estados Unidos, foram estatisticamente semelhantes entre si e apresentaram 5.324 e 5.763 estômatos $/ \mathrm{cm}^{2}$. No grupo "manteiga", as cultivares apresentaram a maior variação para quantidade de estômatos, variando de 4.405 até 9.487 estômatos $/ \mathrm{cm}^{2}$. Neste grupo, as cultivares adaptadas ao calor, Glória e Regina, apresentaram respectivamente 9.487 e 7.973 estômatos/ $\mathrm{cm}^{2}$, diferindo pela maior quantidade de estômatos de todas as demais cultivares do grupo (Tabela 1). As cultivares adaptadas ao verão ameno, IAC 202 e IAC 303, assim como a cultivar Luciana, não adaptada ao cultivo de verão, apresentavam valores intermediários, respectivamente 6.396, 5.689 e 6.017 estômatos/ $\mathrm{cm}^{2}$. A cultivar Sem Rival, sem adaptação ao calor, diferiu significativamente de todas as demais cultivares, apresentando um número de estômatos significativamente menor: 4.403 (Tabela 1). Estes resultados são uma forte evidência da ocorrência de seleção indireta para número de estômatos, quando se faz seleção de cultivares de alface para adaptação ao calor. Como afirmam Hale \& Orcutt (1987), fatores que aumentam a taxa de transpiração, quando há água disponível, também aumentam a tolerância a altas temperaturas. Em alface, Heinen \& van Moolenbroek (1995), por meio de análise de regressão, concluíram que a radiação solar e o calor elevados são fatores que aumentam a quan- 
Tabela 2. Peso de matéria fresca, peso de matéria seca, número de folhas e peso seco na colheita (aos 42 dias do plantio) de dez cultivares de alface. Piracicaba, ESALQ, 1991.

\begin{tabular}{lllllllll}
\hline \multicolumn{1}{c}{ Cultivares } & Grupo & $\begin{array}{c}\text { Peso fresco } \\
\text { (g/planta) }\end{array}$ & $\begin{array}{c}\text { Peso seco } \\
\text { (g/planta) }\end{array}$ & $\begin{array}{c}\text { Número de } \\
\text { folhas/ planta }\end{array}$ & $\begin{array}{c}\text { Peso seco na } \\
\text { colheita } \\
\text { (g/planta) }\end{array}$ & $\begin{array}{c}\text { Tempo para } \\
\text { pendoar } \\
\text { (dias) }\end{array}$ \\
\hline G. Rapids & folha crespa & $121,73 \mathrm{~cd}$ & $6,45 \mathrm{C}$ & 14,16 & $\mathrm{~d}$ & 15,92 & $\mathrm{e}$ & 42 \\
Brisa & folha crespa & $147,66 \mathrm{ab}$ & $8,28 \mathrm{ab}$ & 16,94 & $\mathrm{C}$ & 22,40 & $\mathrm{~cd}$ & 47 \\
Mesa 659 & americana & $147,03 \mathrm{ab}$ & $9,45 \mathrm{a}$ & 12,20 & $\mathrm{~d}$ & $28,74 \mathrm{a}$ & $>60$ \\
G. Lakes & americana & $145,14 \mathrm{ab}$ & $8,96 \mathrm{a}$ & $11,93 \quad \mathrm{~d}$ & $27,17 \mathrm{ab}$ & $>60$ \\
Sem Rival & manteiga & $113,33 \mathrm{~d}$ & $6,25 \mathrm{C}$ & $18,90 \mathrm{bc}$ & 16,75 & $\mathrm{e}$ & 44 \\
Luciana & manteiga & $131,53 \mathrm{bcd}$ & $7,32 \mathrm{bc}$ & $20,82 \mathrm{ab}$ & 20,65 & $\mathrm{~d}$ & 46 \\
IAC 303 & manteiga & $163,73 \mathrm{a}$ & $8,52 \mathrm{ab}$ & $22,69 \mathrm{a}$ & $24,47 \mathrm{bc}$ & 46 \\
IAC 202 & manteiga & $148,91 \mathrm{ab}$ & $8,58 \mathrm{ab}$ & $22,00 \mathrm{a}$ & $23,88 \mathrm{bcd}$ & 48 \\
Glória & manteiga & $137,46 \mathrm{bc}$ & $8,34 \mathrm{ab}$ & $21,37 \mathrm{ab}$ & $24,55 \mathrm{bc}$ & 51 \\
Regina & manteiga & $144,23 \mathrm{ab}$ & $8,64 \mathrm{ab}$ & $22,76 \mathrm{a}$ & $25,50 \mathrm{abc}$ & 52 \\
\hline CV \% & & 13,94 & 15,73 & 11,37 & 13,94 & \\
\hline
\end{tabular}

*/ Médias seguidas de mesma letra nas colunas não diferem estatisticamente entre si a $5 \%$ de probabilidade pelo teste de Tukey.

tidade de água transpirada e evaporada, desde que a água não seja o fator limitante. Para as condições do estado de São Paulo, Ferri (1985) comenta que espécies como milho, feijão ou eucalipto, perdem a mesma quantidade de água por transpiração e este valor oscila entre $3 \mathrm{~mm}$ no inverno e $7 \mathrm{~mm}$ no verão. Considerando que em alface deve ocorrer perda de água semelhante, as cultivares selecionadas para plantio durante o calor devem apresentar uma taxa de transpiração elevada, o que se infere devido ao maior número de estômatos presentes nas alfaces selecionadas para o calor.

Os resultados observados para número de estômatos parecem confirmar aqueles obtidos da análise da espessura das folhas. Encontraram-se diferenças significativas para as cultivares de alface dentro do grupo "americana", pois 'Mesa 659' apresentou uma espessura de folha de $589 \mathrm{~mm}$, resultado significativamente superior ao obtido para 'Grandes Lagos': 423 mm. No grupo "folha crespa", ao contrário não houve diferença significativa entre os resultados observados para as cultivares Grand Rapids e Brisa. No entanto, ficou evidente também no grupo "manteiga" que cultivares adaptadas ao calor se destacaram por possuírem folhas mais grossas. As cultivares Glória e Regina apresentaram folhas com 556 e 439 mm respectivamente, diferindo significativamente de todas as demais cultivares do grupo (Tabela 1). Ainda no grupo "manteiga", as cultivares IAC 202, adaptada a verões amenos, e Luciana, sem adaptação ao calor, mostraram valores para espessura de folha intermediários, estatisticamente semelhantes entre si, mas diferentes das demais cultivares do grupo. É bom lembrar que a cultivar Luciana, mesmo sem adaptação ao calor, também havia apresentado uma quantidade de estômatos significativamente semelhante às cultivares do grupo adaptadas a verões amenos. A cultivar Sem Rival, sem adaptação ao calor, foi aquela que apresentou menor espessura de folha, significativamente inferior às demais cultivares do grupo. Esta mesma cultivar foi a que apresentou o número significativamente menor de estômatos $/ \mathrm{cm}^{2}$ (Tabela 1). A associação entre número de estômatos e espessura das folhas observada neste trabalho é um bom indicativo de que a caracterísitica espessura das folhas seja importante na adaptação das cultivares para condições de cultivo em regiões tropicais, em meses quentes e chuvosos.

A quantidade de clorofila total foi menor nas cultivares do grupo "folha crespa" (Tabela 1). Apesar da clorofila desempenhar papel fundamental no processo de bioconversão de energia (Ferri, 1985), não se observou relação entre esta característica e a adaptação ao calor. Yang et al. (1998) estudaram cultivares de Brassicas chinesas visando de- terminar metodologias que pudessem estar relacionadas na determinação da resistência ao calor. Verificaram que a variação na quantidade de clorofila não poderia ser um índice fisiológico para a resistência ao calor. Tewaki \& Tripathy (1998) propõem que a inibição da biossíntese sob estresse calórico é devida à inibição de algumas enzimas. Assim, é possível que a adaptação ao calor esteja relacionada à ação de enzimas e não a variações na quantidade de clorofila.

$\mathrm{O}$ acúmulo de matéria verde e seca e o número de folhas dentro do grupo "folha crespa" mostrou diferença significativa entre as cultivares de inverno e verão. A cultivar Brisa, adaptada ao calor, acumulou significativamente mais matéria verde e seca e apresentou um número significativamente maior de folhas que a cultivar Grand Rapids, não adaptada ao calor (Tabela 2). No grupo "manteiga" houve diferenças significativas no acúmulo de matéria verde e seca entre as cultivares selecionadas tanto para calor quanto para verão ameno e a cultivar Sem Rival, não selecionada para o calor (Nagai, 1979). Estes resultados mostram que as cultivares selecionadas para calor, quando plantadas em épocas de verão, têm, conforme esperado, ganhos de produtividade significativos comprovados pelo peso seco aos 42 dias de desenvolvimento nas cultivares Glória $(24,55 \mathrm{~g})$, Regina $(25,50)$, IAC 303 $(24,47 \mathrm{~g})$ e IAC $202(23,88 \mathrm{~g})$, em rela- 
ção a Sem Rival (16,75 g). Brunini et al. (1976) em ensaios com a cultivar White Boston, considerada como de adaptação semelhante à cultivar Sem Rival, determinaram que temperaturas entre $21^{\circ} \mathrm{C}$ e $24^{\circ} \mathrm{C}$ estimulam ao pendoamento. Brouwer \& Huyskes (1968) estudaram o desenvolvimento de uma cultivar e um híbrido de alface em salas climatizadas com temperatura e luminosidade controladas e demonstraram que o desenvolvimento vegetativo é interrompido quando aparecem os primeiros sinais de pendoamento. A cultivar Grand Rapids apresentou emissão do pendão floral 42 dias após o plantio, e "Sem Rival' aos 44 dias, indicando que na sexta semana (42 dias) possivelmente já havia se iniciado a fase reprodutiva nestas cultivares, com conseqüente interrupção da fase vegetativa. Nas cultivares adaptadas ao calor ou a verões amenos, a emissão do pendão floral ocorreu mais tarde, aos 51 dias em 'Glória', aos 52 dias em 'Regina', aos 46 dias em 'IAC 303' e aos 48 dias em 'IAC 202'. Assim, o maior acúmulo de biomassa em cultivares adaptadas ao calor deve-se à maior lentidão para se emitir a inflorescência, com prolongamento da fase vegetativa, resultando em maior produtividade na colheita ou final do ciclo (Tabela 2). Esse efeito parece não estar relacionado ao incremento da atividade fotossintética, ou de redução da respiração, pois quando são considerados os resultados obtidos para quantidade de clorofila, não foi observada nenhuma alteração significativa nas cultivares adaptadas ao calor. Entretanto estas cultivares apresentaram aumento significativo do número de estômatos.

Os resultados demonstraram que plantas selecionadas para o pendoamento tardio, em plantios de verão, apresentaram outras características adaptativas que acompanharam o processo de seleção. As modificações fisiológicas mais expressivas foram notadas pelo aumento no número de estômatos nas plantas das cultivares selecionadas para calor e, em relação à morfologia, plantas das cultivares selecionadas apresentaram folhas mais grossas. A seleção para pendoamento tardio resultou em plantas que mantiveram o ritmo de crescimento por mais tempo, alcançando produtividades maiores antes de pendoar.

Analisando o desempenho por grupo varietal, verificamos que as cultivares do grupo "americana" atingiram peso seco na colheita significativamente maior que as cultivares do grupo "manteiga" sem adaptação ao calor e das cultivares do grupo "folha crespa". As cultivares do grupo "americana" não apresentaram sinais de pendoamento até 60 dias do plantio, o que era esperado pois são cultivares tardias. Apresentaram número pequeno de folhas, semelhantes estatisticamente apenas à cultivar Grand Rapids, indicando que é característica do grupo a pequena quantidade de folhas de peso seco unitário elevado.

\section{LITERATURA CITADA}

BROUWER, R.; HUYSKES, J.A. A physiological analysis of the responses of the lettuce variety "Rapide" and its hibrid with "Hamadan" to day-lenght and light intensity. Euphytica, v. 17, p. $245-251,1968$.

BRUNINI, O.; LISBÃO, R.S.; BERNARDI, J.B.; FORNASIER, J.B.; PEDRO JUNIOR M.J. Temperatura-base para alface cultivar "White Boston", em um sistema de unidades térmicas. Bragantia, Campinas, v. 35 , n. 19, p. 213219, 1976.

DAMARANY, A.M. Breeding for heat tolerance in the Balady cultivar of lettuce (Lactuca sativa L.). Assiut Journal of Agricultural Sciences, v. 20 , n. 4, p. 159-172, 1989. /Resumo em CAB Abstracts on CD-ROM, 1992/

FERRI, M.G. Fisiologia vegetal. São Paulo: EPU, 1985. 362 p.

GONG, F.R. Selection of heat resistant head lettuce strains 9544-1 and 9608-2. Acta Agriculturae Shangai, v. 14, n. 3, p. 35-40, 1998. /Resumo em CAB Abstracts on CDROM, 1998/08-01/1999/

HALE, M.G.; ORCUTT, D.M. The physiology of plants under stress. Nova York: John Wiley \& Sons Inc., 1987. 206 p.
HEINEN, M; van MOOLENBROEK, J. Water balance of lettuce grown on sand beds. Acta Horticulturae, v. 401, p. 517-24, 1995.

LIHONG, G.; SHIJUN, L. Physiological bases of heat tolerance in regenerated lettuce. Journal of Nanjing Agricultural University, v. 17, n. 2, p. 23-27, 1994. /Resumo em CAB Abstracts on CD-ROM, 1995/

LISBÃO, R.S. Alface. In: JORGE, J.A.; LOURENÇÃO, A.L.; ARANHA, C. (Ed.) Instruções agrícolas para o Estado de São Paulo. 5 ed. Campinas: Instituto Agronômico, 1990.

MESSEGUER, R.; GANAL, M.; VICENTE, M.C.; YOUNG, N.D.; BOLKAN, H.; TANKSLEY, S.D. High resolution RFLP map around the root knot nematode resistance gene (Mi) in tomato. Theoretical and Applied Genetics, v. 82 n. 5 p. 529-36, 1991.

NAGAI, H. Obtenção de novas cultivares de alface (Lactuca sativa L.) resistentes ao mosaico e ao calor. I-Brasil 48, 202 e 221. Revista de Olericultura, Brasília, v. 17, p. 129-137, 1979.

PINTO, C.A.B.P.; COSTA, C.P. Melhoramento de hortaliças. Piracicaba: ESALQ, Departamento de Genética, 1977. 319 p.

RYDER, E.J. Breeding vegetable crops. Gainesville: University of Florida, 1982. 116 p.

SETZER, J. Atlas climático e ecológico do Estado de São Paulo. São Paulo, Comissão Interestadual da Bacia do Paraná-Uruguai, 1966, $618 \mathrm{p}$.

SMITH, W.K.; McCLEAN, T.M. Adaptative relationship between leaf water repellency, stomatal distribution, and gas exchange. American Journal of Botany, v. 76, n. 3, p. 465469, 1989.

TEWAKI, A.K.; TRIPATHY, B.C. Temperaturestress induced impairment of chlorophyll biosynthetic reactions in cucumber and wheat. Plant Physiology, v. 117, n. 3, p. 851-858, 1998.

VECCHIA, P.T.D.; KIKUCHI, M. "Gloria": nova cultivar de alface lisa resistente ao florescimento prematuro. Horticultura Brasileira, Brasília, v. 7, n. 2, p. 29-30, 1989.

WHITAKER, T.W.; RYDER, E.J. Lettuce production in the United States. Washington: USDA, 1974. 218 p.

WITHMAN, F.H.; BLAYDES, D.F.; DENIN, R. Experiments in plant physiology. New York: Von Nostrand, 1971. 456 p.

YANG, LW; WANG, J.; LIANG, H.; CHEN, J. The research on identification technology of heat tolerance of chinese cabbage (Brassica campestris L., SSP. Pekinensis). Acta Horticulturae, v. 467, p. 227-31, 1998. 